\title{
CONICAL FLOWER CELLS REDUCE SURFACE GLOSS AND IMPROVE COLOUR SIGNAL INTEGRITY FOR FREE-FLYING BUMBLEBEES
}

\author{
Saskia Wilmsen', Adrian G. Dyer ${ }^{2,3}$ \& Klaus Lunau' \\ ${ }^{1}$ Institute of Sensory Ecology, Biology Department, Heinrich-Heine-University Düsseldorf (Germany)

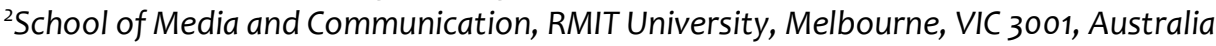 \\ ${ }^{3}$ Department of Physiology, Monash University, Clayton, VIC 3800, Australia
}

Journal of Pollination Ecology, 28(9), 2021, pp 108-126

DOI: $10.26786 / 1920-$

$7603(2021) 606$

Received 22 December 2020, accepted 06 April 2021

*Corresponding author:

Klaus.Lunau@hhu.de

\begin{abstract}
Colour signals of flowers facilitate detection, spontaneous preference, discrimination and flower constancy by important bee pollinators. At short distances bees orient to floral colour patterns to find a landing platform and collect nutrition, potentially improving the plants' reproductive success when multiple flowers are visited sequentially. In addition to pigments and backscattering structures within the petals' internal layers, the epidermal micro-structure of the petals' surface may also influence petal reflectance properties and thus influence overall colour patterns via optical effects. Gloss, i.e., shine caused by specular reflections of incident light from smooth surfaces, may for example alter the visual appearance of surfaces including flowers. We classify the epidermal surface properties of petals from 39 species of flowering plants from 19 families by means of a cell shape index, and measure the respective surface spectral reflectance from different angles. The spontaneous behavioural preferences of free flying bumblebees (Bombus terrestris) for surfaces with different micro-textures was then tested using specially prepared casts of selected flower petals. We specifically tested how the petal colour as function of the angle of incident light, surface structure and bee approach angle influences bumblebees' spontaneous choices for artificial flowers. We observe that bumblebees spontaneously prefer artificial flowers with conical-papillate micro-structures under both multidirectional illumination and under spotlight conditions if approaching against the direction of spotlight, suggesting conical cells help promote constant signals by removing gloss that may confound the integrity of colour signalling.
\end{abstract}

Keywords-Bumblebee, gloss, flower, colour, epidermal micro-structure, petal

\section{INTRODUCTION}

Floral colour is one of the most important signals for bumblebees to find and visit flowers (Kugler 1935; Lunau \& Maier 1995; Smithson \& McNair 1996; Lunau et al. 1996; Gumbert 2000; Muth et al. 2015; Lunau 2016; Reverté et al. 2016; Wester \& Lunau 2017; Ison et al. 2019), and it is now well appreciated that colour is a perception of a particular observer that is strongly influenced by its specific sensory capabilities (Maxwell 1857; Kühn 1927; Daumer 1956; Menzel 1979; Dyer 2012; Kemp et al. 2015; Garcia et al. 2017). In this context, a colour signal is defined as a trait that has evolved to allow for an effective visual communication between plants as the information sender, and flower visitors as the receiver of signal information (Sprengel 1793; von Frisch 1915; Kevan 1978). As such, potential colour information must fit four core conditions to be considered as a signal (i) effectively transmit information from the signaller to the receiver, (ii) have evolved specifically for this particular purpose, (iii) the signaller should benefit from the production of the signal, and (iv) the receiver should change its behaviour due to the perception of the signal (Smith \& Harper 2003; Bradbury \& Vehrencamp 2011). In recent years there has been rapid growth in the appreciation that surface structure of plant flower petals may produce a variety of optical effects that may contribute to the colour perception of bee pollinators. Proposed optical structures include 
iridescence (Glover \& Whitney 1999; Vignolini et al. 2015), specular reflections (gloss) (Galsterer et al 1999; Vignolini et al. 2012; Whitney et al. 2012; van der Kooi et al. 2017), and "halos" (Moyroud et al. 2017), although how such optical effects may fit a formal definition for flower colour signalling has only been tested in relatively few behavioural studies (Whitney et al. 2016; Dyer et al. 2007; Garcia et al. 2019; see van der Kooi et al. 2019 for review). For example, structural colours such as iridescence have been proposed to be important signals that may be present in flowering plant species, since it has been shown that free flying bumblebees can learn such information with appetitive-aversive conditioning in controlled laboratory conditions (Whitney et al. 2009c), despite the fact that structural colours might corrupt colour identity due to changing appearance from different viewing angles (Whitney et al. 2016). Indeed, when considering the wide range of approach angles bees may encounter flowers in a natural setting it is unlikely that structural colours could be regarded as signals rather than cues and thus would not have specifically evolved for the purpose of plant pollinator communication (Garcia et al. 2019).

Gloss potentially contains information of the form of an object, since gloss is produced in the symmetrical angle to the one of incoming light. For example, each sphere with a smooth surface produces gloss that can be used by the beholder to identify the spherical form. The sparkle in the eyes is produced by the spherical eyeball and an essential feature of the eye: the eyespots of butterfly wings are mimicking potential predators' eyes including the sparkle (Blut et al. 2012). Interestingly, some flowers that mimic pollinators with a glossy surface in order to attract conspecifics are mimicking the gloss by white and UV-reflecting spots (Johnson \& Midgley 1997; Ellis \& Johnson 2009) or are glossy themselves (Vignolini et al. 2012). Recently, Lunau et al. (2020) proposed a signalling function of gloss from nectar, nectar guides, and nectar-mimicking structures.

The colour of flowers is affected by light that is transmitted, absorbed and/or backscattered from internal structures of the flowers (Stavenga \& van der Kooi 2016; van der Kooi et al. 2016), and by light that is reflected from the epidermal cells' surface (van der Kooi et al. 2019). Whereas the reflection of backscattered light is diffuse and altered in its wavelength composition due to absorption by pigments, the reflection of light from the surface is directional and less altered in its wavelength composition and thus appears "white" to a human observer, and presumably achromatic to bees. The epidermis cell shape is principally responsible for the amount of incident light refracted into the flower petal and the amount reflected directly from the flower petal surface. Specular reflectance consists of light reflected from a surface where the angle of incidence of the light and the angle of reflection are equal (Chadwick \& Kentridge 2015). Given the appropriate viewing angle, in flower petal epidermises with conical cells, each cell produces only a very small specular highlight, whereas in epidermises with flat cells the highlights can be as large as the epidermis cells. The potential glossiness of surfaces is mediated by direct reflection of incident light and may thus lead to a dynamic or variable visual perception of the surface, dependent of the viewing angle of an observer. However, even in human's perception of gloss and colour is only partially understood, and here it appears that colour saturation and thus colour perception may be influenced by the glossiness of a surface, although such processing may be by separate sensory channels (Chadwick \& Kentridge 2015). For example, by using photography and a polarizing filter to remove gloss reflected from the surface of food there is a change in our perception of the colour of fruit (Landy 2007; Motoyoshi et al. 2007). The perceived colour of glossy surfaces is thus potentially a mixture of light changing in its wavelength composition after absorption by pigments, backscattering, and light unchanged in its wavelength composition after reflection from the surface (van der Kooi et al. 2017, 2019).

Besides visual cues, the surface micro-texture of flowers also provides tactile cues for bees (Kevan \& Lane 1985). It is known that bees can perceive surface sculpturing upon contact by means of their antennae (Kevan \& Lane 1985; Erber at al. 1998). Since petal surface sculpturing might affect the grip of bees on flowers, it is interesting to know whether bees can use gloss, a factor that is associated with surface sculpturing, as an indicator for grip on a flower (Papiorek et al. 2014). 


\section{MATERIALS AND METHODS}

In petals with conical epidermal cells the effect of colour on bees is potentially intensified by the focusing of light into the pigment layer (Kay et al. 1981; Gorton \& Vogelmann 1996; Glover \& Martin 1998; Comba et al. 2000; Baumann et al. 2007; Whitney et al. 2011 b; Papiorek et al. 2014; Gkikas et al. 2015). However, how this affects the colour perception of bees in a biologically significant way remains unclear. For example, Dyer et al. (2007) found that bumblebee choices for Antirrhinum majus flower colour was not significantly affected in a diffuse light setting considering wild type flowers with conical petals, or Mixta mutants that had flat cell shapes. As a result of the conical epidermis shape, the reflected light from the mesophyll may also scatter and diffuse light which can produce a velvet and matte texture of the petal (Kay et al. 1981; Kay 1988; Glover \& Martin 1998). In contrast, flat surfaces produce a uniform and directional reflection of incident light, which may be perceived as gloss dependent of the viewing angle (Kay et al. 1981; Kay 1988; van der Kooi et al. 2014; van der Kooi et al. 2017). Gloss is largely independent of the wavelength, but strongly dependent on the angle of the incident light, and causes "whitish" reflections likely to be a dynamic component of flower petals when the flower visitor changes its position relative to the glossy surface (Hurlbert 2007; Land 1977; Skorpski \& Chittka 2011).

The salience of colours in flowers displaying glossy surfaces has not yet studied; one might expect that bumblebees either ignore the gloss or respond to the spatial change of the glossy area with viewing angle, or respond to the change of the overall colour due to the gloss. The change of the colour of a glossy flower due to the viewing angle might represent a dynamic cue attracting the approaching bees' attention, a changeable and thus less reliable cue, or a generally altered colour cue. Lunau (1990) demonstrated that bumblebees possess an inherent preference for spectrally pure colour signals, which implies that a mixture of glossy "white" light reflections might dilute the colour and result in a less spectrally pure colour. Discrimination of flowers displaying glossy surfaces seems critical, since the surface colour changes due to the orientation of the flower, the position of the sun and the approach flight direction of the flower visitors (Galsterer et al. 1999).

In the current study we seek to experimentally test if the level of gloss from the surface of flower petals is a reliable signal for promoting spontaneous preferences in free-flying bumblebees (Bombus terrestris) considering different illumination directions, and bee approach angles to a flower. We thus initially survey a number of flowers with SEM imaging to identify likely flower structures that produce various levels of gloss due to the underlying petal surface structure, and make positive epoxy casts of representative species to enable psychophysics type behavioural experiments with free flying bumblebees. We specifically test the hypothesis that gloss influences the spontaneous preferences of bees for flowers.

\section{MICRO-TEXTURES OF FLOWERS}

The flowers of 39 available plant species were selected to obtain a good cross section from the Botanical Garden of the Heinrich-HeineUniversity Düsseldorf from June to August 2015. The flowers were stored in an airtight box with wet towel in a refrigerator at $8^{\circ} \mathrm{C}$ to prevent a premature aging process and shrinking of the flower material until measurements were made.

From the flowers' petal a $5 \mathrm{~mm}$ x $20 \mathrm{~mm}$ rectangular section was cut out using a razor blade (Wilkinson Sword Classic; Wilkinson Sword $\mathrm{GmbH}$, Solingen, Germany). From this section up to 40 micro-slices were cut out, as far as possible with a thickness about $0.06 \mathrm{~mm}$ corresponding to 3 rows of epidermal cells. The best 5 microsclices were put in water between object holder and cover slip to defer the leak of the cell sap and were analysed under a microscope (Zeiss Axio Scope.A1, Carl Zeiss Microimaging $\mathrm{GmbH}$, Göttingen, Germany). Photos were taken using a microscope camera (Zeiss AxioCam MRc, Carl Zeiss MicroImaging GmbH, Göttingen, Germany) and the software Zen 2 (blue edition 2011, Carl Zeiss Microscopy GmbH, Jena, Germany). The photos were used to quantify the epidermal cell shape using a Shape-index (Papiorek et al. 2014). The Shape-index is the product of apical, lateral and basal angular measures of a cell (Fig. 1): 


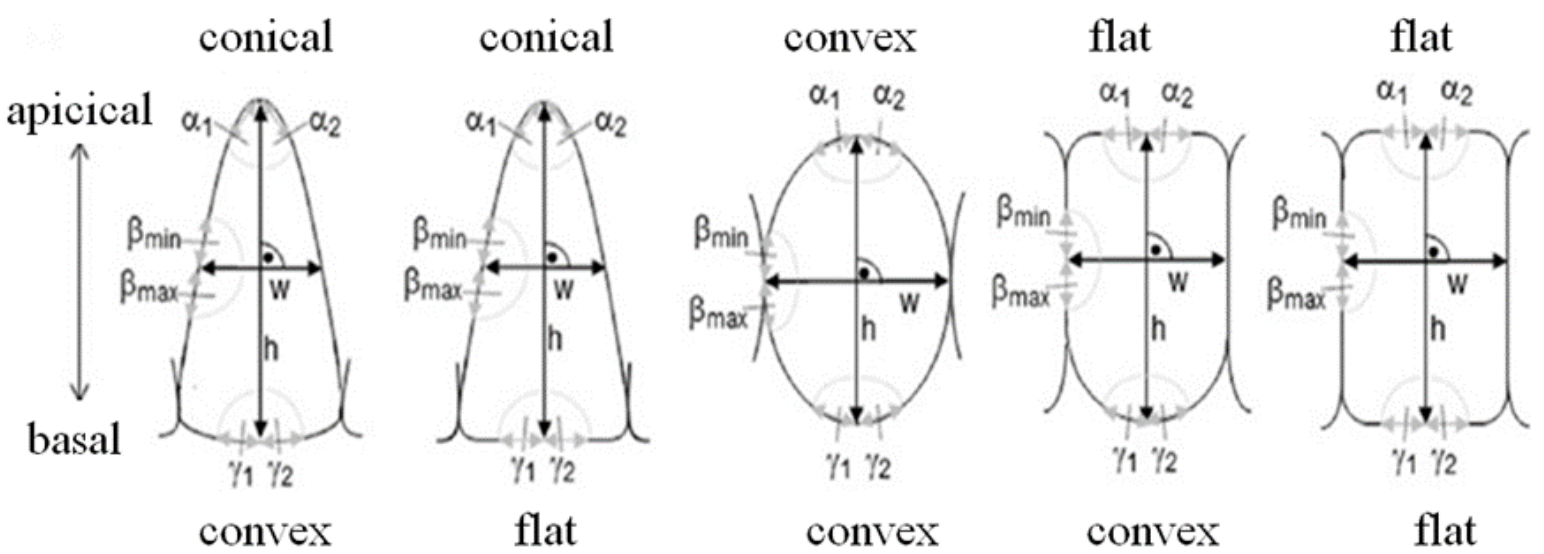

Figure 1: Scheme of different cell shapes of epidermis cells with adjustment of the apical, lateral and basal angular measures for the calculation of the Shape-index.

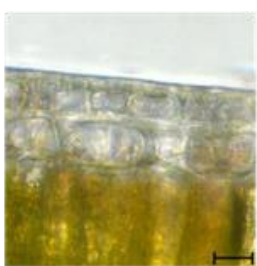

Lenticular-smooth Roughly rectangular shape without vaulted up- and underside

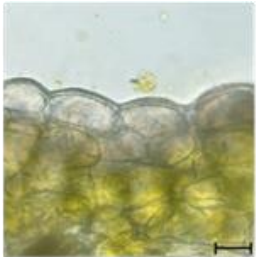

Lenticular

Roughly rectangular shape with lenticular vaulted up- and underside

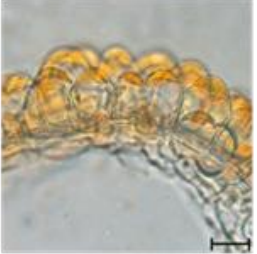

Lenticular-conical

Prevalent lenticular

shape with a conical tip at the upside

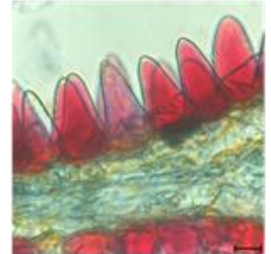

\section{Conical}

Roughly triangular

shape with wide base

without constriction

of lateral cell walls

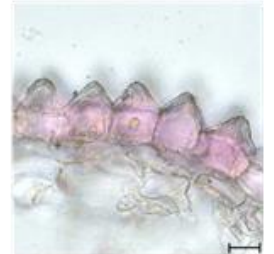

Conical-papillate

Prevalent conical

with strong

constriction of lateral

cell walls

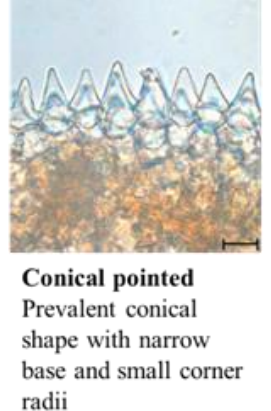

radii

Figure 2: Classification of epidermis cells due to their shape in micro-slices. The scale bar indicates $20 \mu \mathrm{m}$.

$$
\mathrm{S}=\frac{\alpha 1+\alpha 2}{180} * \frac{\gamma 1+\gamma 2}{180} * \frac{\beta \min }{\beta \max }
$$

The Shape-index was calculated for the 39 species of flowering plants by averaging the arithmetic mean from 5 micro-slices each. The cell shape was classified according to Kay et al. (1981) into 6 categories, which were conical pointed, conical-papillate, conical, lenticular-conical, lenticular and lenticular-smooth (Fig. 2). The conical pointed category includes the most sharply pointed cell shape, the conical-papillate cell types are prevalent marked by a conical shape with strong constrictions of the lateral cell walls, whereas cells of the conical categories did not show these clear constrictions. Cells of the lenticular types provided the distinctive lenticular shape, the lenticular-conical cell shape is similar but with a conical tip on the upper-side (Kay et al. 1981). The characteristic of the lenticular-smooth epidermal cells is the approximately rectangular shape without vaulted up- and underside resulting in a flat surface.

\section{SPECTRAL REFLECTANCE AND LOCI IN THE COLOUR HEXAGON}

Reflection measurements of the flowers were used to study the dependence of spectral reflectance from the micro-texture of the epidermal cells. A spectrophotometer (USB 4000, Ocean Optics, Inc. Ostfildern, Germany) was connected with the light source (UV-VIS-NIR LIGHTSOURCE, Ocean Optics, DH - 2000 - BAL) via a coaxial glass fibre (QR 400-7-UV-VIS, Ocean Optics, Inc. Dunedin, Fl. USA). Before each measurement started the spectrophotometer was calibrated with a black standard (black PTFE powder, Spectralon $®$, reflection of $2 \%$, reflection standard SRS-02-010, Labsphere, Inc. North Sutton, USA) and a white standard (white PTFE powder, Spectralon ${ }^{\circledR}$, reflection of $99 \%$, reflection standard SRS-99-010, Labsphere, Inc. North Sutton, USA). The recordings were taken from $1.2 \mathrm{~cm} \times 1.8 \mathrm{~cm}$ sized pieces of petal cut-outs with a scalpel of the same flower from which the Shape- 
index was calculated. These specimens were measure on an achromatic (including UV) grey cardboard.

The petal sections were placed on a lab-lift (Hebebühne Swissboy 110, Rudolf Grauer AG, Degersheim, Switzerland) in order to adjust a constant distance to the detector head which both emitted light from the source and detected the light reflected from the sample. To simulate different angles of incident light the detector head was placed at angles of $45^{\circ}$ and $90^{\circ}$ to the plane of the sample. All measurements were made in a darkened room.

A modified setup was used to measure the gloss of the artificial flowers: instead of a detector head emitting incident and recording reflected light, the incident light was illuminating the probe via a separate fibre at an angle of $45^{\circ}$ to the plane of the sample; the detector head was mounted to a goniometer and measurements of the spectral reflectance were taken for angles of $45^{\circ}$ and $90^{\circ}$ to the incident light. The spectral reflectance curves are shown in the supplemental Fig. S4.

The spectral reflectance curves were used to calculated the colour loci in the colour hexagon (Chittka 1992) using the spectral sensitivity of the photoreceptors of the bumblebee Bombus terrestris (Peitsch et al. 1992), standard daylight D65 (Wyszecki \& Stiles 1982) and the green plotter foil as background for adaptation of the photoreceptors. For more information about the calculation of the colour loci see Lunau et al. (1996) and Rhode et al. (2013).

The spectral reflectance properties of the flowers were classified with the following parameters: colour hue, colour contrast, spectral purity, intensity and green contrast.

The colour hue $(\mathrm{H})$ was determined by the highest spectral reflectance (Rmax) of the spectral reflectance curve and given as the $(\lambda)$ in the considered range of wavelength from $300-700 \mathrm{~nm}$ :

$$
\mathrm{H}=\lambda(\operatorname{Rmax})
$$

The colour contrast was determined as the Euclidean distance between the flower colour locus, and the colour locus of the centre in the colour hexagon (Chittka 1992) representing the background colour locus.
The spectral purity (SP) according to Lunau et al. (1996) was determined in the colour hexagon as the distance between the flower colour locus and the colour locus of the background colour divided by the distance between the corresponding spectral locus and the background colour locus (Papiorek et al. 2013):

$$
\mathrm{SP}=(\mathrm{HD}(\mathrm{LC}-\mathrm{LB})) /(\mathrm{HD}(\mathrm{SL}-\mathrm{LB}))
$$

with $(\mathrm{HD}(\mathrm{LC}-\mathrm{LB}))=$ distance in hexagon units between the locus of the flower colour and the locus of the background, and (HD (SL-LB)) = distance in hexagon units between the corresponding spectral locus and the locus of the background

The green contrast (GC) was determined based on the assumption that the bees' photoreceptors are adapted to the background colour and then half-maximally excited (Laughlin 1981; Chittka 1992). It is thus the difference in the calculated excitation of the green receptor for the flower and the green background.

$$
\mathrm{GC}=\left|\mathrm{EG}_{\mathrm{G}}-0.5\right|
$$

The intensity (B) of the flower colours was calculated as the quotient of the sum of the calculated excitation of the UV-, blue-, and green photoreceptors type and the number of photoreceptors types as defined by Spaethe et al. (2001).

$$
\mathrm{B}=\left(\sum \mathrm{Euv}_{\mathrm{u}} \mathrm{E}, \mathrm{EG}\right) / 3
$$

\section{MANUFACTURING OF ARTIFICIAL FLOWERS}

Due to its suitable size and micro-textures artificial flowers were produced from casts of the upper-side of a petal of the rose 'Agnes Bernauer' (Rosaceae) and the upper-side of a green leaf of Magnolia grandiflora (Magnoliaceae) as well as the upper-side and underside of a petal of Tibouchina urvilleana (Melastomataceae). These four natural patterns were complemented with three different artificial flowers with factitious surface structures. These artificial flowers were composed of the flat bottom of a small glass dish $(\varnothing 38 \mathrm{~mm})$, one of it was directly used as a flat dummy and two more dummies were produced by strewing glass pellets with different diameters $(150 \mu \mathrm{m}<\varnothing<300 \mu \mathrm{m}$; $420 \mu \mathrm{m}<\varnothing<840 \mu \mathrm{m}$; Worf Glaskugeln $\mathrm{GmbH}$, Mainz, Germany) into the glass dish. The small glass dish was the initial position for all dummies, also the flower petals and glass pellets were fixed 
on it with double-faced adhesive tape (tesafix ${ }^{\circledR}$ 51570, Tesa SE, Norderstedt, Germany). By this way artificial flowers with a completely smooth, a slightly rough, and a highly rough surface were manufactured.

The primed glass dish with the different surface structures was placed in a larger glass dish and a low viscous silicone casting compound (viscosity < 950mPas; (TFC4001, Troll factory, Riede, Germany) was poured over the structure at room temperature. The crosslinking of this twocomponent system takes place at ambient temperature so that the dummies were not exposed to fission products of the chemical reaction or heat exposure thus the micro-texture of the petals were preserved. After 40min hardening time the two glass dishes were removed and the negative in the block of silicone was filled with $5 \mathrm{~g}$ of an epoxy mixture of 2 parts resin, 1 part hardener (Typ 4305 and hardener 313, DD Composite $\mathrm{GmbH}$, Bad Liebenwerda, Germany) admixed with $10 \%$ ultramarine pigment paste (RAL 5002, DD Composite GmbH, Bad Liebenwerda, Germany). The mixture was carefully homogenized and stirred with a scoop to avoid air bubbles. The hardening time was 24 hours. From each negative 20 positives were manufactured. The positives were used as artificial flowers; a $2 \mathrm{~mm}$ deep hole $(\varnothing=5 \mathrm{~mm})$ was drilled into the middle of the circular artificial flowers to serve as a sugar water bowl as reward for the bumblebees.

\section{LIGHT AND SCANNING ELECTRON MICROSCOPY}

Photographs were taken to visualize the gloss from the surface of the artificial flowers for the human eye with a camera (Panasonic, Lumix, Panasonic Marketing Europe $\mathrm{GmbH}$, Hamburg, Germany) under multidirectional light conditions consisting of 9 fluorescent tubes (BIOLUX T8, L 58 W/965, OSRAM GmbH, München, Germany) and in a spotlight-setup (LED 9414, Zweibrüder Optoelectronics, Solingen, Germany) with an angle of incident light of $45^{\circ}$ and different approach angles of the camera $\left(90^{\circ}, 85^{\circ}, 75^{\circ}, 65^{\circ}\right.$, $55^{\circ}$ und $45^{\circ}$ ).

The similarity between natural petals and the casts were checked by means of scanning electron microscopy (Leo 1430 VP, Carl Zeiss NTS GmbH, Oberkochen, Germany) in the Center for Advanced Imaging of the Heinrich-Heine-
University Düsseldorf. The natural petal of Tibouchina urvilleana was fixed for 48 hours in a Schaffer mixture consisting of 1 part formaldehyde $35 \%\left(\mathrm{CH}_{2} \mathrm{O}\right.$, Sigma-Aldrich ${ }^{\circledR}$, München, Germany) and 2 parts ethanol $96 \%\left(\mathrm{C}_{2} \mathrm{H}_{5} \mathrm{OH}\right.$, Merck ${ }^{\circledR}$, Darmstadt, Germany) and then washed 3 times in ethanol (96\%). The natural sample and the artificial flowers, which replicate the upper-side of the petal from Tibouchina urvilleana, Rosa 'Agnes Bernauer', the leaf of Magnolia grandiflora and the underside of the petal of Tibouchina urvilleana were sputtered with gold. The scanning in vacuum $(\mathrm{p} \leq$ $10-3 \mathrm{~Pa}=10-5 \mathrm{mbar}$ ) lasted $30 \mathrm{~min}$ to ensure highresolution photos (software ZEN, Carl Zeiss AG, Oberkochen, Germany) with maximal resolution of $1 \mathrm{~nm}$.

\section{BUMBLEBEE KEEPINC}

The bumblebees, Bombus terrestris (BIObest, Westerlo, Belgium) were kept from June to November 2015 in a laboratory of the Institute of Sensory Ecology of the Heinrich-Heine-University Düsseldorf. Two colonies were used consecutively to perform the tests. The nest box was connected to a flight box (height $x$ width $x$ depth.: $81 \mathrm{~cm} \times 62 \mathrm{~cm}$ $x 60 \mathrm{~cm}$ ) in which the bumblebees were fed with Biogluc ${ }^{\circledR}$ from a wick connected to a Falcon tube. Honeybee-collected pollen (Heinrich Holtermann KG, Brockel, Germany) was given directly into the nest to ensure the protein supply of the colony. The room had no windows so that daylight could not influence the foraging behaviour of the bumblebees. The room was illuminated by fluorescent tubes (BIOLUX T8, L 58 W/965, OSRAM GmbH, München, Germany) from 9:00 a.m. to $6: 00$ p.m., the room temperature varied between $22.7^{\circ} \mathrm{C}$ and $23.9^{\circ} \mathrm{C}$, the relative air humidity between $17 \%$ and $22 \%$.

EXPERIMENTAL SETUP UNDER MULTIDIRECTIONAL ILLUMINATION

The behavioural tests under multidirectional light refer to the natural conditions on a cloudy day, whereby strong gloss effects are excluded. In contrast, the spotlight experiments were intended to simulate direct sunlight with strong shadows and gloss on smooth surfaces. The experimental arena (height $\mathrm{x}$ width $\mathrm{x}$ depth $=175 \mathrm{~cm} \times 146 \mathrm{~cm} \times$ $100 \mathrm{~cm}$ ) for the setup under multidirectional illumination was confined by a mosquito net and had a table (height $\mathrm{x}$ width $\mathrm{x}$ depth $=125 \mathrm{~cm} \times 70 \mathrm{~cm}$ $x 40 \mathrm{~cm}$ ) for the presentation of the artificial flowers 


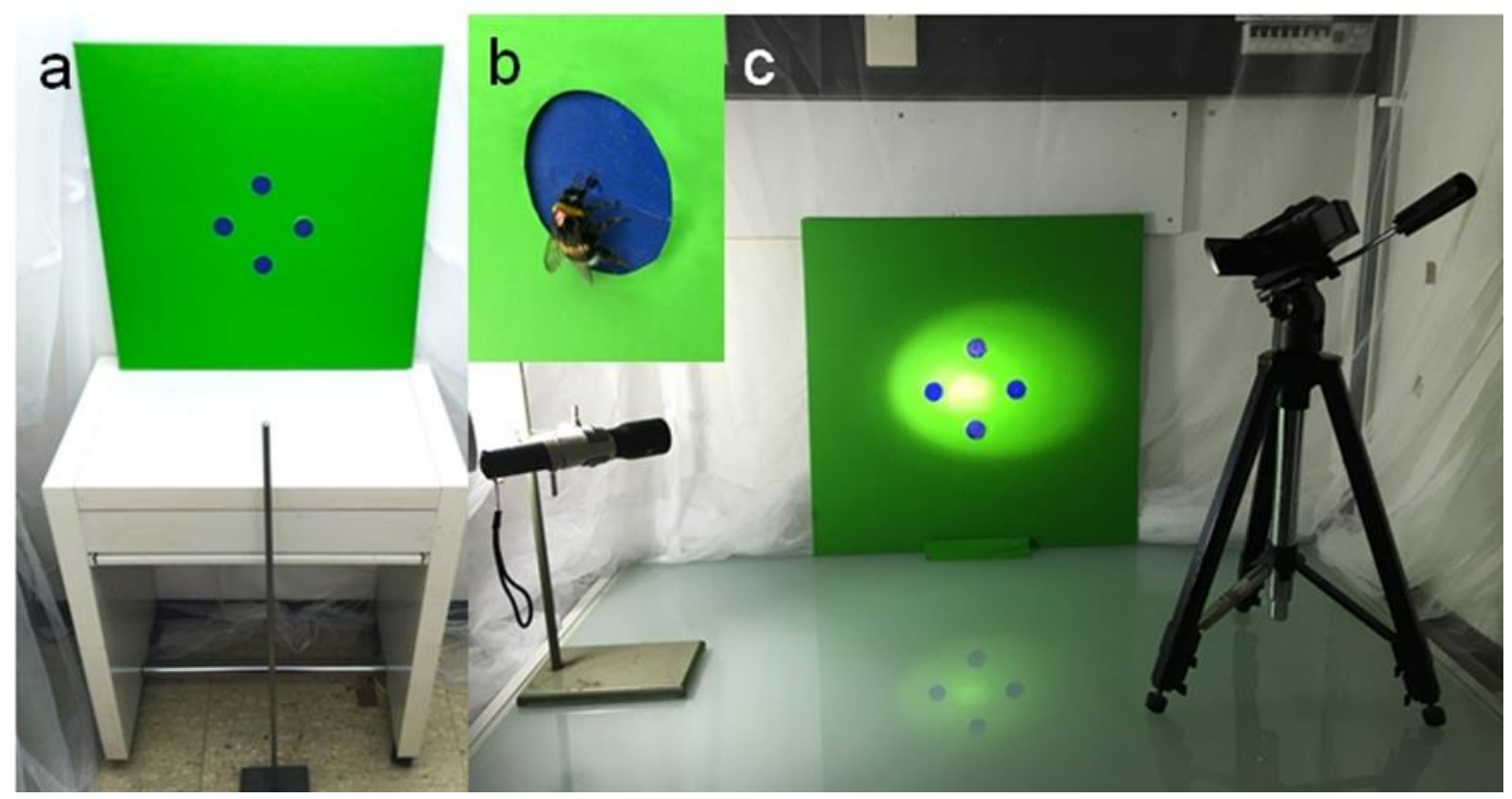

Figure 3: Experimental setups: a) Diffuse illumination and vertical presentation of artificial flowers. Foreground with bar indicating the starting point for individual bumblebees. b) Inset shows a landed bumble bee drinking sugar water. c) Spotlight illumination and vertical presentation of artificial flowers. Note the torch at left.

(Fig. 3). The artificial flowers were presented against a green board covered with a matte PVC foil (Plotterfoil Oracal 631, Exhibition Cal, 064 gelbgrün, RAL 6018, ORAFOL® Europe GmbH, Oranienburg, Germany). The green board $(60 \mathrm{~cm} x$ $60 \mathrm{~cm})$ had 4 circular cut-outs $(\varnothing=38 \mathrm{~mm})$ to insert the artificial flowers. The multidirectional illumination was provided by 9 fluorescent tubes (BIOLUX T8, L 58 W/965, OSRAM GmbH, München, Germany). The intensity of the illumination amounted to about 2000lux measured with a luxmeter (BEHA 93408, BEHA Amprobe, Glottertal, Germany) near the artificial flowers.

To simulate horizontal and vertical presentation of natural flowers, the green board was presented on the table either in horizontal or in an almost vertical position at an angle of $85^{\circ}$ from the horizontal table surface to the rear wall. This inclination ensured that the bumblebees could sit on the artificial flowers while drinking sugar water. A video-camera (Panasonic HC-V707, Panasonic, Hamburg, Germany) mounted to a tripod was used to record the bumblebees' behaviour. The foragers, marked with an Opalithplate, were captured individually on their way from the nest to the foraging cage and carried into the experimental arena with a Drosophila tube. A stand at a distance of $42 \mathrm{~cm}$ from the experimental setup marked the starting point to ensure uniform conditions.

\section{EXPERIMENTAL SETUP WITH SPOTLIGHT ILLUMINATION}

The experimental arena for the setup under spotlight illumination was in a flight room with a table (height $\mathrm{x}$ width $\mathrm{x}$ depth $=100 \mathrm{~cm} \times 126 \mathrm{~m} \times$ $80 \mathrm{~cm}$ ) for the presentation of the artificial flowers (Fig. 3). The relocation of the test arena was necessary to avoid disturbance of the bumblebees in the flight box by changing light conditions. The green board was presented on the table either in horizontal or in an almost vertical position. The spotlight was provided by a LED torch (LED 9414, Zweibrüder Optoelectronics, Solingen, Germany) mounted on a laboratory stand placed on the table at an angle of $45^{\circ}$ to the board and directed to the middle of the board so that the four presented artificial flowers were completely illuminated. A video-camera (Panasonic HC-V707, Panasonic, Hamburg, Germany) mounted to a tripod to record the bumblebees' behaviour was placed opposite to the torch. The bumblebees were released at a distance of $42 \mathrm{~cm}$ either from the torch for an approach in the direction of the incident light source or from the video-camera for an approach against the direction of the incident light. The intensity of the illumination near the artificial flowers was measured with the luxmeter and 
showed differences in illuminance between 700 and 2000lux.

\section{EXPERIMENTAL PROCEDURE}

All experiments were done with flower-naive bumblebees marked with numbered tags for individual identification (Opalith-Plättchen, Holtermann, Brockel, Germany). We used motivated free flying bees that spontaneously elected to travel from the nesting box to the arena in order to reduce pre-training (see below), and each bee was tested during one foraging bout in the arena before it was allowed to go to the nest.

Video-recording was started when the bumblebee was released in the flight arena. A landing was counted if the bumblebees touched the artificial flower with all six legs. It was checked that bumblebees never interrupted their landing following contact of the artificial flowers with their antennae. Bumblebees that did not decide to land on artificial flowers for $4 \mathrm{~min}$ were excluded. Individual bumblebees were used in only one experiment. In the experiments with spotlight conditions, individual bumblebees were used for tests in and against the direction of the spotlight.

In all experiments 4 artificial flowers were presented simultaneously (Table 1). In quadruple choice tests four different artificial flowers were presented either horizontally or vertically, which were a biomimetic replica of a natural rose petal and three artificial micro-structures, fine, rough, and smooth (Table 1, Fig. 4). In dual choice tests two different artificial flowers were presented twice and vertically; these were either biomimetic replica of the upper-side of a petal of Tibouchina urvilleana and of the upper-side of a green leaf of Magnolia grandiflora or of the underside of a petal of Tibouchina urvilleana and of the upper-side of a green leaf of Magnolia grandiflora (Table 1, Fig. 4).

Before the tests the bumblebees were pretrained 1-3 times on the vertical setup, but with 4 achromatic grey artificial flowers made of cardboard and rewarded with a 50\% sugar solution presented in Eppendorf caps. As soon as a bumblebee had visited all 4 grey artificial flowers during a single training trial, it was marked and released into the nest to empty the honey stomach. On its way from the nest to the flight room it was captured for testing. The number of bumblebees tested varied among experiments due to the size of the nest and available workers.

In all experiments only the first choice was evaluated to determine spontaneous choice behaviour. In the experiments with multidirectional illumination each individual bumblebee was tested 4 times in order to test positional preferences and learning effects (Table 1; Supplement Fig. S2). After each landing on an artificial flower the bumblebee was allowed to imbibe the sugar water before it was captured. Then the artificial flower was cleaned and refilled with $7 \mu \mathrm{l}$ of $50 \%$ sugar solution. The entire setup was turned for $90^{\circ}$ before the bumblebee was released again to reveal possible position preferences. By this way it was ensured that all artificial flowers were presented once in each position. After the fourth test the bumblebee was released into the nest and excluded from further experiments.

\begin{tabular}{lllll}
\hline Test Nr. & Illumination & Presentation & $\begin{array}{l}\text { Artificial } \\
\text { flowers }\end{array}$ & $\begin{array}{l}\text { Bees tested } \\
(\mathrm{n})\end{array}$ \\
\hline 1 & mult & horizontal & sm, fi, ro, rp & 16 \\
2 & mult & vertical & sm, fi, ro, rp & 16 \\
3 & mult & vertical & td, gl, td, gl & 20 \\
4 & mult & vertical & td, tb, td, tb & 20 \\
5 & spoti & horizontal & sm, fi, ro, rp & 10 \\
6 & spota & horizontal & sm, fi, ro, rp & 10 \\
7 & spoti & vertical & td, gl, td,gl & 20 \\
8 & spota & vertical & td, gl, td,gl & 20 \\
9 & spoti & vertical & td, tb, td, tb & 20 \\
10 & spota & vertical & td, tb, td, tb & 20 \\
\hline
\end{tabular}

TABLE 1: Test series with different combinations of artificial flowers (sm = smooth; $\mathrm{fi}=$ fine, produced with small glass pellets; ro $=$ rough, produced with large glass pellets, $\mathrm{rp}=$ rose petal; td = Tibouchina petal adaxial; tb = Tibouchina adaxial, $\mathrm{gl}=$ Magnolia green leaf) and illumination (mult = multidirectional; spoti $=$ spotlight in the direction of approach; spota = spotlight against the direction of approach); number of bumblebee workers tested. 


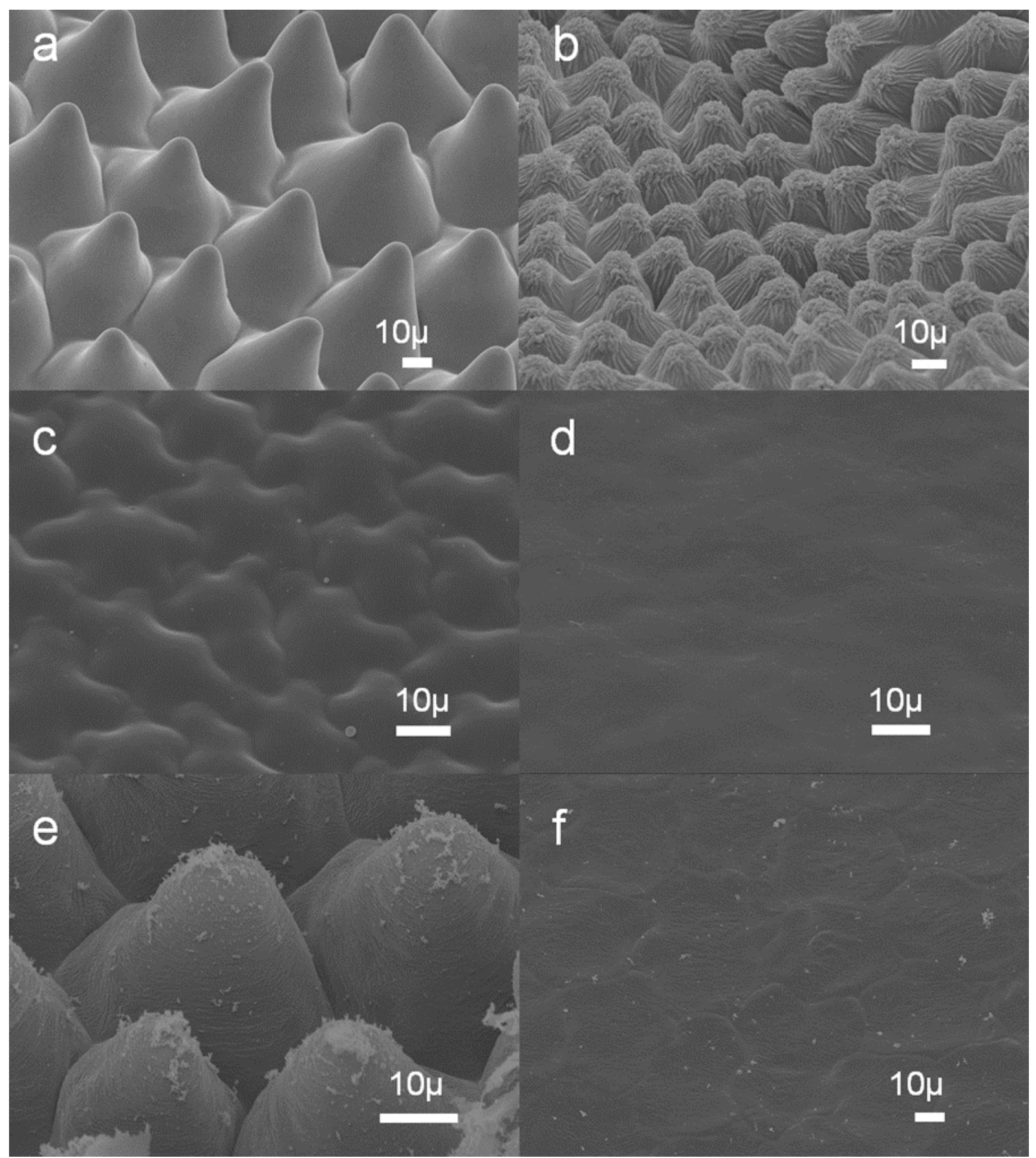

Figure 4: Scanning electron micrographs of a-d) the biomimetic surfaces of the artificial flowers and of e,f) the adaxial and abaxial side of the original petal of Tibouchina urvilleana ; a) adaxial epidermal micro-structure of Tibouchina urvilleana cast: the conical cells show no cuticula folds; b) adaxial epidermal micro-structure of the Rose, Agnes Bernauer' petal cast: the conicalpapillate cells show strong cuticula folds; c) abaxial epidermal micro-structure of $T$. urvilleana cast: the lens-shaped cells show no cuticula folds; d) adaxial epidermal micro-structure of a green leaf cast of Magnolia grandiflora; e) adaxial epidermal microstructure of the natural petal of T. urvilleana; $f$ ) abaxial epidermal micro-structure of the natural petal of $T$. urvilleana. The scale bars are located in every picture in the right lower corner.

In the experiments with spotlight illumination each individual bumblebee was tested 8 times (Table 1). Each bumblebee was tested 4 times approaching the artificial flowers in direction of the incident light and 4 times approaching the artificial flowers against the direction of the 

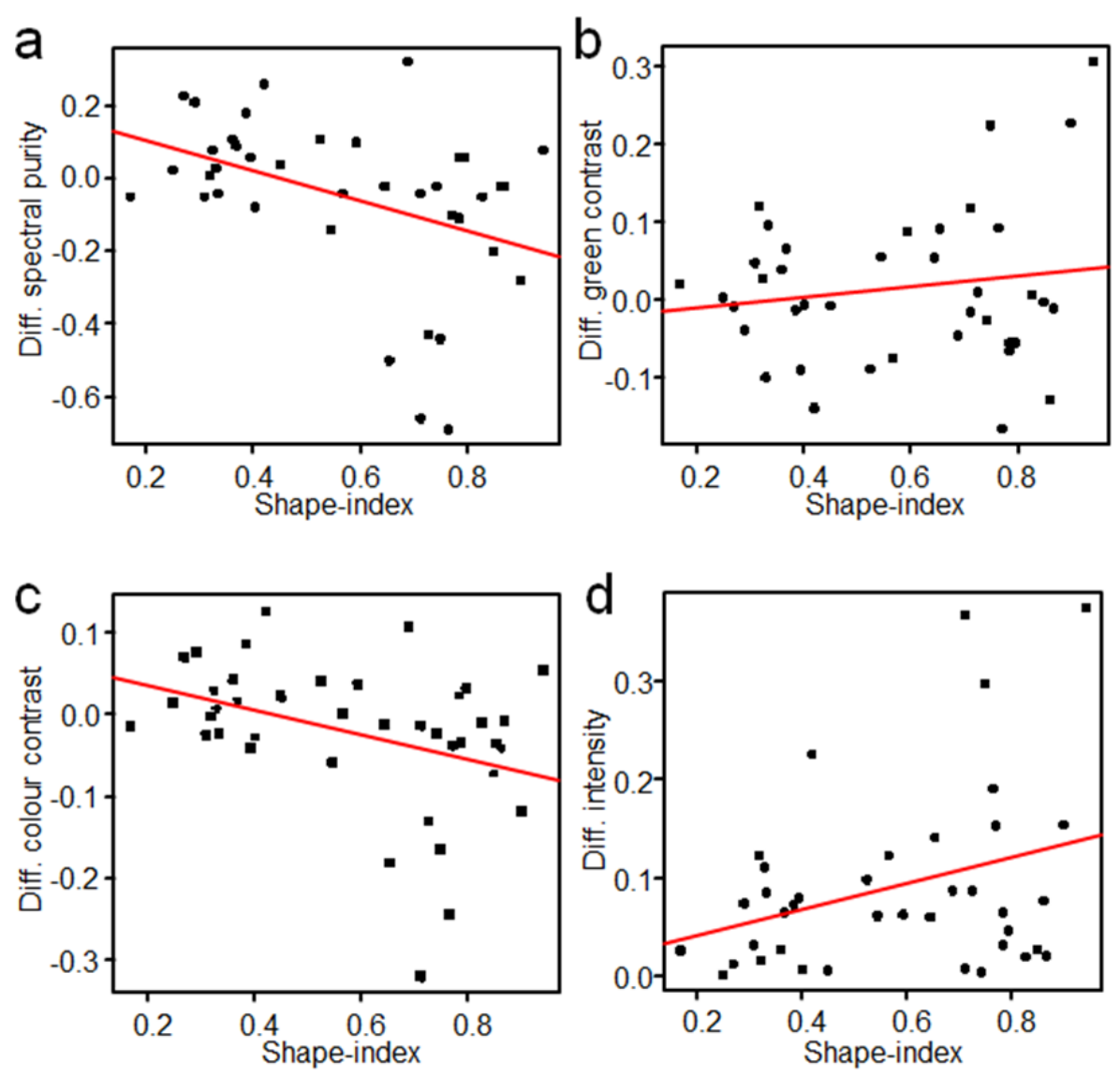

FIGURE 5: Linear regression of the difference between visual parameters taken under measurement angles of $45^{\circ}$ or $90^{\circ}$ and the shape-index; a) spectral purity (SP) according to Lunau et al. (1996) (SRL) ( $R=$ $-0.401 ; \mathrm{t}=-2.66 ; \mathrm{df}=37 ; \mathrm{P}=$ $0.011)$; b) green contrast $(R=$ $0.155 ; \mathrm{t}=0.956 ; \mathrm{df}=37 ; \mathrm{P}=$ $0.345) ; c)$ colour contrast $(R=-$ $0.371 ; \mathrm{t}=-2.433 ; \mathrm{df}=37 ; \mathrm{P}=$ $0.020)$; $d)$ intensity $(R=0.322$; $\mathrm{t}=$ 2.068; $\mathrm{df}=37 ; \mathrm{P}=0.046)$; Pearson's correlation. incident light. In each of the 8 tests, the bumblebee was only allowed to land on one artificial flower. The setup was turned for $90^{\circ}$ between the tests (Table 1).

\section{EVALUATION OF THE DATA}

The data evaluation was done with the statistic software R-Studio (Version 0.98.1103 - (C) 2009-2014 RStudio, Inc., www.rstudio.com). The correlation between Shape-index and the various colour parameters was analysed with a Pearson test.

The photos of the artificial flowers taken under spotlight illumination were used for the estimation of gloss effects with Adobe Photoshop CS2 (Adobe Systems Software Ireland Limited, Dublin, Ireland). The areas of the artificial flowers were converted into the number of pixels. Using the tool 'Lichter' and with a tolerance of 30 out of maximally 255 units the number of white pixels was counted.

The evaluation of the behavioural data was analysed with a two-tailed Chi-Square test with four categorical variables in quadruple choice tests and two categorical variables in quadruple choice tests. In the quadruple choice experiments a twotailed Chi-Square test was applied as a post-hoc test.

\section{RESULTS}

\section{EPIDERMAL MICRO-STRUCTURES}

The 39 examined plant species exhibited petals with different epidermal cell shapes from lenticular-smooth over lenticular to conical with intermediated structures (Table 2). The cell shape of 23 investigated epidermal surfaces could be classified as lenticular and 16 as conical in different manifestations. The smaller the shape index value the more conical is the structure of the epidermal cells. Calystegia sepium for instance was the flower with the smallest value of shape-index of 0.17 , consequently it was classified as conical-pointed. By contrast, the flattest cell shape was observed at Magnolia soulangeana with a shape-index of 0.94 , which led to the classification as lenticular-smooth.

Scanning electron microscopy revealed clear differences of the micro-texture of the adaxial petal epidermis cast of Tibouchina urvilleana, the adaxial petal epidermis cast of the rose hybrid 'Agnes 
Table 2: Examined plant species with associated shape-index, the classification of cell shapes, green and colour contrast, spectral purity and intensity according to the measuring angles of $45^{\circ}$ and $90^{\circ}$.

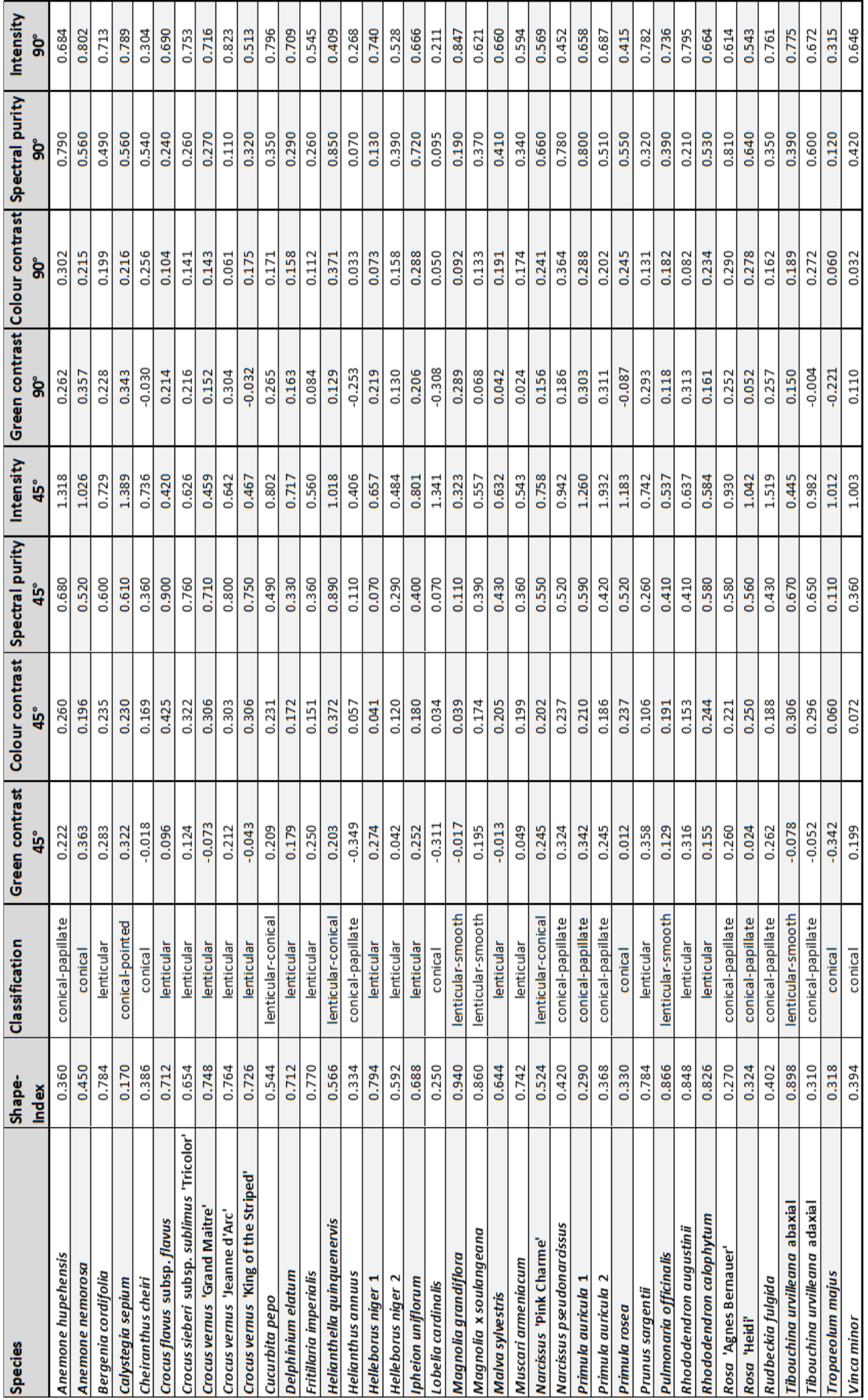


Bernauer', abaxial petal epidermis cast of Tibouchina urvilleana and adaxial green leaf epidermis cast of Magnolia grandiflora. The difference between the casts and the natural surfaces of adaxial petal epidermis of Tibouchina urvilleana and adaxial epidermis of Magnolia grandiflora are small indicating a good quality of the casts (Fig. 4).

ANGLE-DEPENDENT SPECTRAL REFECTION DEPENDENT OF EPIDERMAL MICRO-STRUCTURES

To test how different angles of incident light affect the reflection properties of epidermal microstructures, the dependence of selected flower parameters, spectral purity, green contrast, colour contrast, and intensity derived from the spectral analysis of the flower petals were each plotted against shape index.

The difference of the spectral purity of a similar petal area measured at an angle of $45^{\circ}$ and at an angle of $90^{\circ}$ is significantly correlated with the shape-index (Pearson's correlation; Fig. 5a). With an increasing shape-index value, the difference of spectral purity measured at the respective angles of $45^{\circ}$ or $90^{\circ}$ is significantly decreasing. The difference in the green contrast measured at the respective angles of $45^{\circ}$ or $90^{\circ}$ is not significantly correlated with the shape-index (Fig. 5b). Contrary to the green contrast result, the difference in colour contrast measured at either angle is significantly negatively correlated with the shape-index (Fig. $5 c)$. The difference in intensity measured at angles of $45^{\circ}$ or $90^{\circ}$ is significantly positive correlated with the shape-index (Fig. 5d).

The percentage of white pixels, assumed to be caused by gloss, varies between $0.01 \%$ and $51.48 \%$ in the photos taken of the artificial flowers under different light conditions and angle (Supplement Table S1; Supplement Fig. S1). The casts of the conical epidermis cells of petals of the rose hybrid and of Tibouchina urveillana have lower percentages of white pixels under all illumination conditions compared to the man-made surfaces and the casts of the flat epidermis cells of petals of Tibouchina urveillana and the green leaf of Magnolia grandiflora (Table 3). Moreover, the percentage of white pixels in the six photos taken under different light conditions and camera angles is below $0.1 \%$ in the conical upper-side of the petal epidermis of Tibouchina urveillana and below $1.0 \%$ in the rose petal and varies at minimum around $10 \%$ in all other artificial flowers (Table 3).

SPONTANEOUS PREFERENCE OF BOMBUS TERRESTRIS UNDER MULTIDIRECTIONAL LIGHT CONDITION

In the quadruple choice experiments four different artificial flowers, a biomimetic replica of a natural rose petal (conical) and three artificial micro-structures, rough, fine, and smooth (Table 1) were presented simultaneously. When presented vertically under multidirectional light conditions, the bumblebees show a significant spontaneous preference for the artificial flowers displaying the micro-texture of the rose petal and the rough and fine micro-textures over those displaying the smooth micro-texture (Fig. 6).

In a dual choice experiment the bumblebees significantly preferred artificial flowers displaying the conical micro-texture of the upper-side of a Tibouchina urvilleana petal over those displaying the smooth micro-texture of a Magnolia grandiflora green leaf under multidirectional light conditions (Fig. 7, but in another experiment did not prefer artificial flowers displaying the conical microtexture of the upper-side of a Tibouchina urvilleana

Table 3: Percentage of white pixels in digital photos of the artificial flowers taken under different light conditions and angle.

\begin{tabular}{llllllll}
\hline $\begin{array}{l}\text { Light condition } \\
\text { Camera angle }\end{array}$ & $\begin{array}{l}\text { Rose } \\
\text { petal }\end{array}$ & $\begin{array}{l}\text { Glass rough, } \\
\text { large pellets }\end{array}$ & $\begin{array}{l}\text { Glass fine, } \\
\text { small } \\
\text { pellets }\end{array}$ & $\begin{array}{l}\text { Smooth } \\
\text { surface }\end{array}$ & $\begin{array}{l}\text { Tibouchina } \\
\text { petal, conical }\end{array}$ & $\begin{array}{l}\text { Tibouchina } \\
\text { petal, } \\
\text { smooth }\end{array}$ & $\begin{array}{l}\text { Magnolia } \\
\text { green leaf, } \\
\text { smooth }\end{array}$ \\
\hline $\begin{array}{l}\text { Multidirectional } 45^{\circ} \\
\text { Multidirectional 90 }\end{array}$ & $0.11 \%$ & $9.50 \%$ & $4.75 \%$ & $0.16 \%$ & $0.02 \%$ & $0.05 \%$ & $0.37 \%$ \\
In spotlight $45^{\circ}$ & $0.17 \%$ & $9.74 \%$ & $6.65 \%$ & $0.03 \%$ & $0.03 \%$ & $0.17 \%$ & $0.21 \%$ \\
In spotlight 90 & $0.01 \%$ & $5.00 \%$ & $3.17 \%$ & $0.08 \%$ & $0.08 \%$ & $0.09 \%$ & $0.11 \%$ \\
Against spotlight $45^{\circ}$ & $0.15 \%$ & $7.22 \%$ & $4.59 \%$ & $0.01 \%$ & $0.01 \%$ & $0.68 \%$ & $0.09 \%$ \\
Against spotlight 90 $90^{\circ}$ & $0.02 \%$ & $7.73 \%$ & $11.38 \%$ & $26.65 \%$ & $0.10 \%$ & $14.49 \%$ & $51.48 \%$ \\
\hline
\end{tabular}


petal over those displaying the lens-shaped microtexture of the underside of a Tibouchina urvilleana petal (Fig. 7).

SPONTANEOUS PREFERENCES OF BOMBUS TERRESTRIS UNDER SPOTLIGHT CONDITIONS

The impact of the angle of a directional light source on the attractiveness of micro-structures for bumblebees were studied in experiments with horizontally presented artificial flowers, in which the bumblebees approached the artificial flowers either from the direction of the spot light, or against it.

With spotlight illumination the bumblebees did not show any spontaneous preference when the artificial flowers, i.e., a biomimetic replica of a natural rose petal and three artificial microstructures, fine, rough, and smooth (Table 1), were displayed horizontally and the bumblebees were approaching from the direction of the spotlight. However, when they were approaching against the direction of the spotlight the bumblebees significantly preferred the artificial flower displaying the micro-texture of the rose petal and that displaying the rough micro-texture over those displaying the fine and smooth micro-textures (Fig. 8). This difference in behaviour in dependence of lighting conditions shows significant changes in bumblebee choices were visual mediated.

In a dual choice experiment the bumblebees significantly preferred artificial flowers displaying the conical micro-texture of the upper-side of a Tibouchina urvilleana petal over those displaying the smooth micro-texture of a Magnolia grandiflora green leaf only if approaching against the direction of incident spot light, but not if approaching in the direction of incident spot light (Fig. 9). Similarly, the bumblebees significantly preferred artificial flowers displaying the conical micro-texture of the upper-side of a Tibouchina urvilleana petal over those displaying the smoother micro-texture of the underside of a Tibouchina urvilleana petal only if approaching against the direction of incident spot light (Fig. 9). This result indicates an effect on the visual behaviour of the bumblebees.

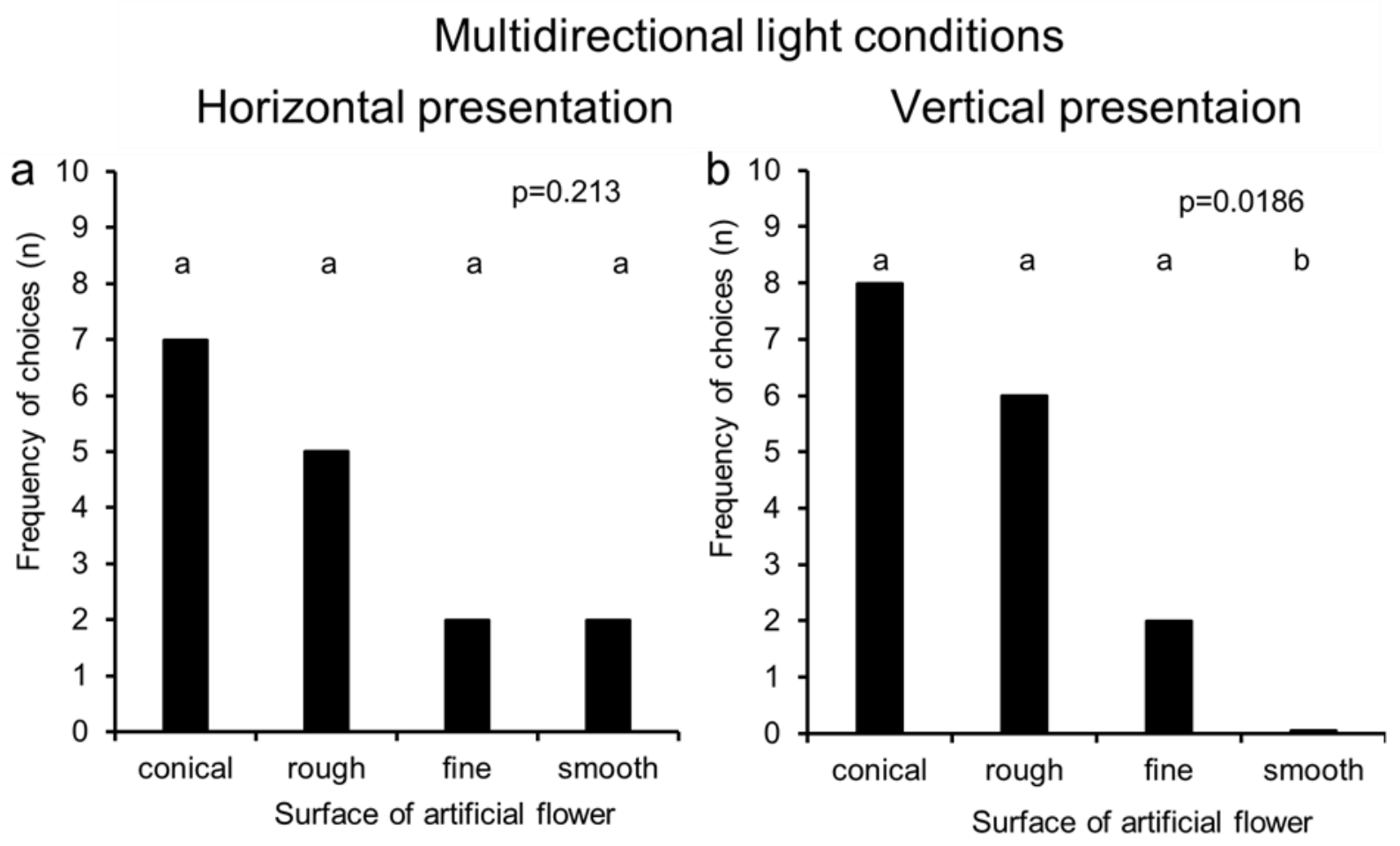

Figure 6: First choices of 16 Bombus terrestris workers at a) horizontally and b) vertically presented artificial flowers under multidirectional light conditions. Abbreviations for artificial flowers are as follows: conical = replica of rose petal; rough = microtexture produced by large glass pellets; fine $=$ micro-texture produced by small glass pellets; smooth $=$ smooth surface. Statistics: $P$-values refer to a Chi-Square test with four categorical variables. Different letters above indicate significant differences with $P$ $<0.05$ between categories. 


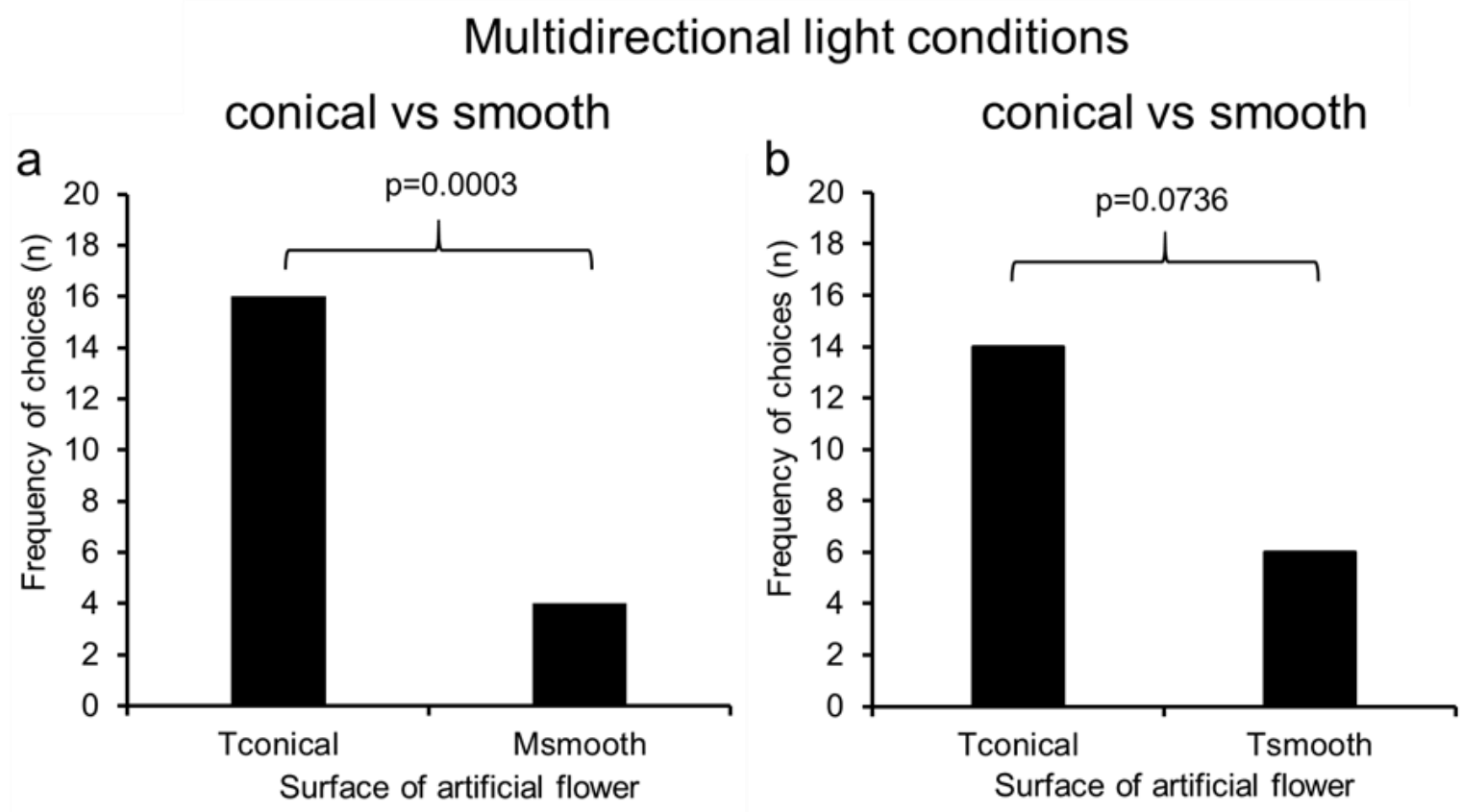

Figure 7: First choices of 20 Bombus terrestris workers at vertically presented artificial flowers under multidirectional light conditions. a) Dual choice between biomimetical replicas of the upper-side of a Tibouchina petal and a Magnolia green leaf, and b) between biomimetical replicas of the adaxial and abaxial side of a Tibouchina petal. Abbreviations: Tconcical = conical microtexture of upper-side of Tibouchina urvilleana petal; Tsmooth = smooth micro-texture of underside side of Tibouchina urvilleana petal; Msmooth = smooth micro-texture of upper-side of Magnolia grandiflora green leaf. Statistics: $P$-values refer to a ChiSquare test with two categorical variables.

\section{Spotlight conditions}

\section{in direction of bee}

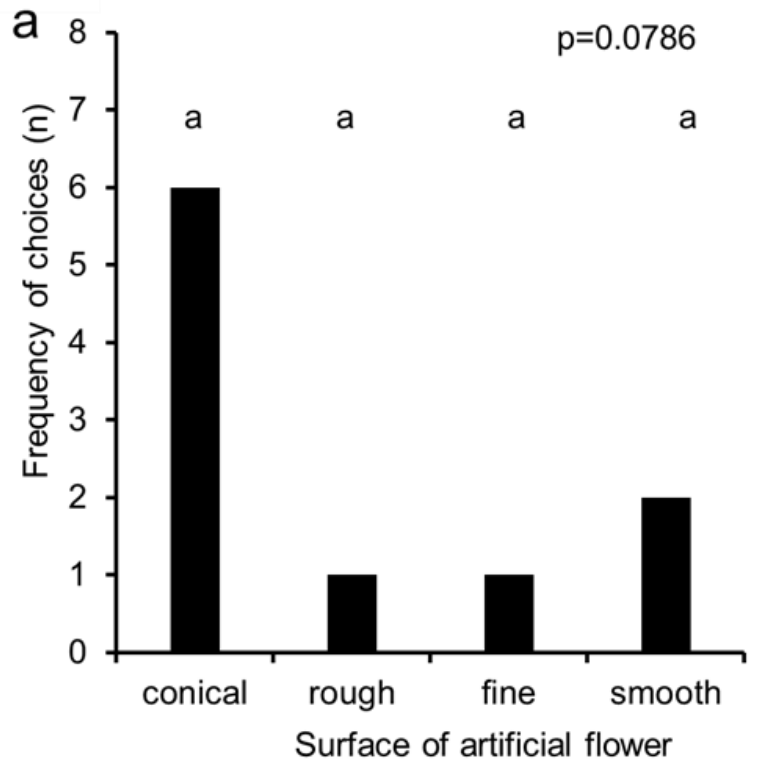

against direction of bee

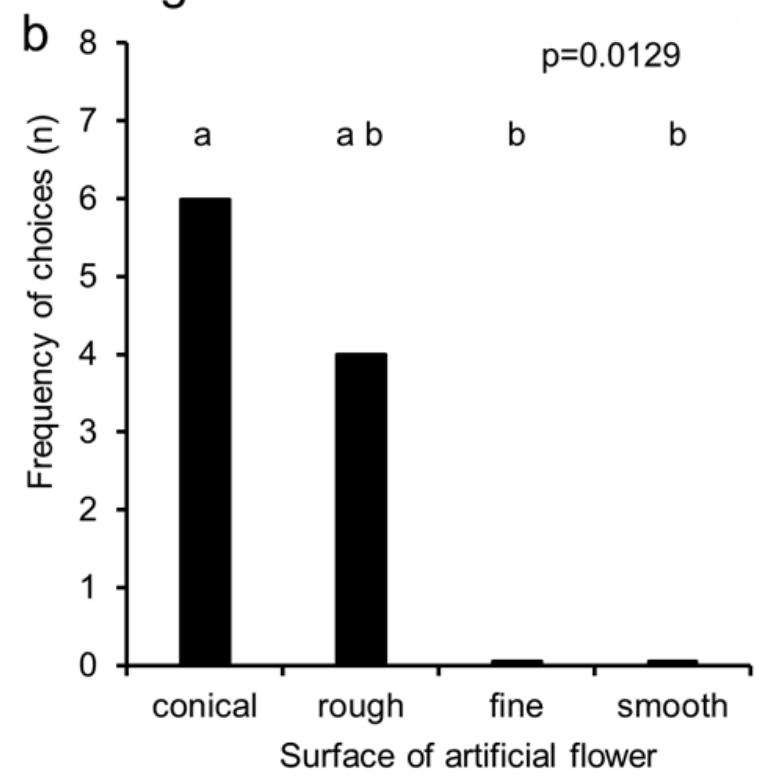

Figure 8: Landing frequency of 10 Bombus terrestris workers at horizontally presented artificial flowers under spot light conditions when approaching a) in, and b) against the direction of incident light. Abbreviations for artificial flowers are as follows: conical = replica of rose petal; rough = micro-texture produced by large glass pellets; fine = micro-texture produced by small glass pellets; smooth = smooth surface. Statistics: $P$-values refer to a Chi-Square test with four categorical variables. Different letters above indicate significant differences with $P<0.05$ between categories due to the Wilcoxon-Test without error correction. 

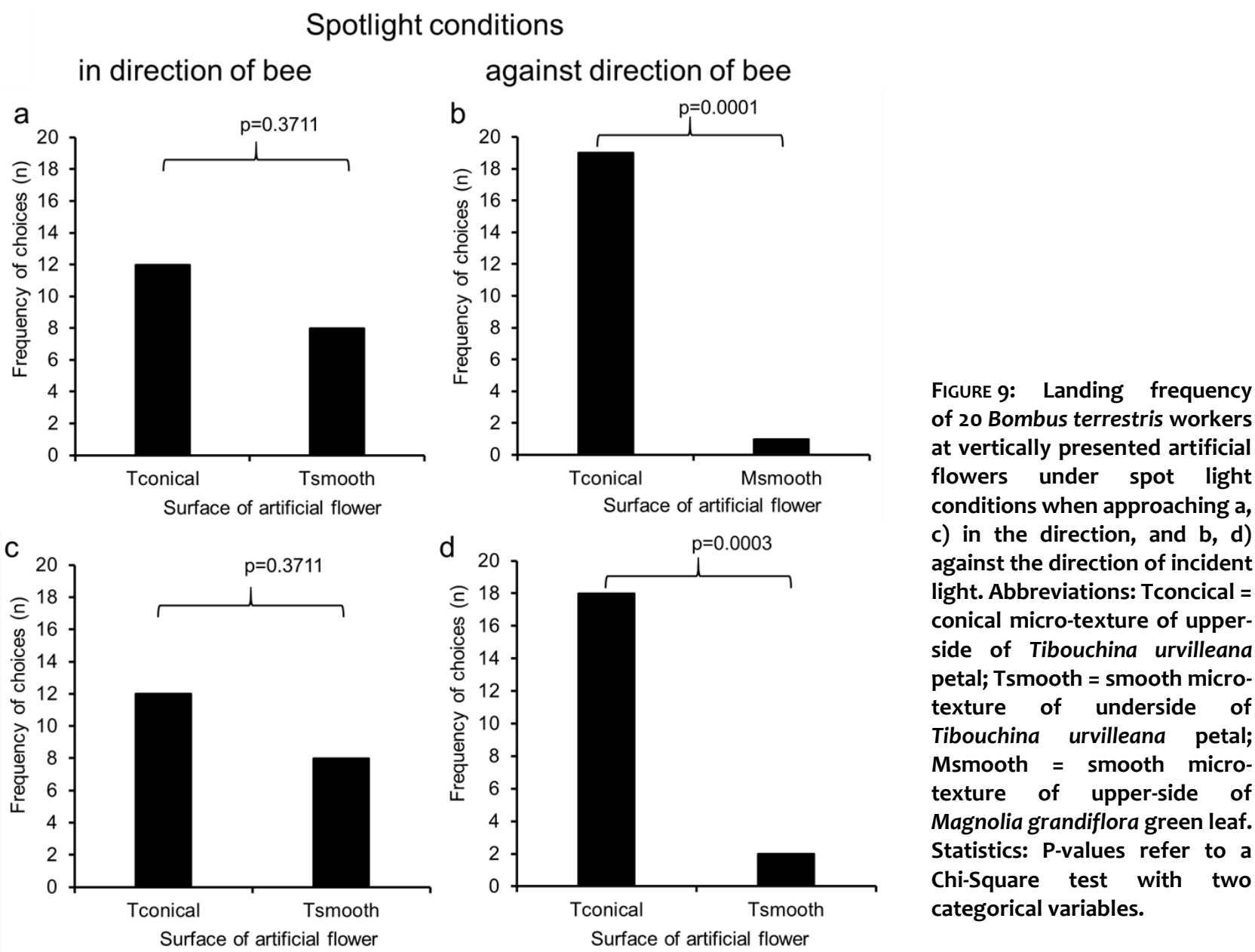
conditions when approaching a, c) in the direction, and b, d) against the direction of incident light. Abbreviations: Tconcical = conical micro-texture of upperside of Tibouchina urvilleana petal; Tsmooth = smooth microtexture of underside of Tibouchina urvilleana petal; Msmooth = smooth microtexture of upper-side of Magnolia grandiflora green leaf. Chi-Square test with two categorical variables.

Position preferences of the bumblebees were not found in any of the experiments (Supplement Fig. S2). Experienced bumblebees performing the $2^{\text {nd }}, 3^{\text {rd }}$, and $4^{\text {th }}$ rewarded choices more or less maintain their initial preference or exhibit a less pronounced preference for structured microtextures (Supplement Fig. S3 and Table S2)

\section{DISCUSSION}

Flowering plants typically have petal cells with a variety of shapes ranging from flat-shaped through rounded to conical-shaped that are thought to offer an advantage for promoting efficient visitations via insect pollinators (Kay et al. 1981; Gorton \& Vogelmann 1996; Glover \& Martin 1998; Comba et al. 2000; Whitney et al. 2011a; Gkikas et al. 2015). Interestingly, flat cells on flower petals are less frequently observed in nature, representing only about $10 \%$ of tested flowering plant species (Kraaij \& van der Kooi 2019), strongly suggesting a selective advantage for having more conical shaped cells. Classic explanations for the evolution of conical cells have included improving grip for insects handling flowers (Whitney et al. 2009a, 2009b; Alcorn et al. 2012), modulating temperature through optical effects (Comba et al. 2000; Whitney et al. 2011a; Vignolini et al. 2015), modulating wettability (Whitney et al. 2011c), hydrophobicity (Garcia et al. 2020), increasing of the surface for scent emission (Whitney et al. 2011 a; Moyroud \& Glover 2016), enabling self-cleaning (Whitney et al. 2011a; Moyroud \& Glover 2016) and/or visual signalling that may enhance a capacity for discrimination or detection (Whitney et al. 2016). Visual signalling seems a very plausible driver of an evolutionary process as it is well established that flowering plants have frequently evolved pigment-based colour signals that are optimally suited to either bee (Chittka and Menzel 1992; Dyer et al. 2012), bird (Shrestha et al. 2013) or fly vision (Shrestha et al. 2016, 2019). Despite the various hypotheses for the evolutionary explanation of conical petal epidermal cells, the explanation of direct visual signalling communication via iridescence, gloss, or 
other structural colour effects does not fit with behavioural evidence that structural colours are unreliable in complex natural conditions, where the position of the sun as the principle light changes, and indeed insects must approach flowers from a seemingly infinite number of approach angles and/or inclination viewpoints which would render changing structural colours an unreliable cue compared to pigment based colours (Lunau 2016; Garcia et al. 2019; Kraaij \& van der Kooi 2019).

In the current study we sourced a number of flowering plant species which had a variety of conical cell shapes and used an established cell shape index (Papiorek et al. 2014) to test for correlations between index values and key visual descriptors for bees including spectral purity, Gcontrast, colour contrast or intensity (Lunau 1990; Rhode et al. 2013). The smaller the shape index value the more conical is the structure of the epidermal cells; for example, Calystegia sepium flower petal cells had the smallest shape-index value of 0.17 and conical-pointed cell shapes, whilst Magnolia soulangeana had flat cells and a shape-index of 0.94 . For spectral purity and colour contrast there were significant negative correlations with shape index, suggesting that more pronounced cell shape served to improve the integrity of colour signals. There was no significant correlation between G-contrast and index values suggesting cell shape plays no role on flower detection, consistent with previous behavioural research (Dyer et al. 2007). There was, however, a significant positive correlation between intensity and index; suggesting that flat cells reflect more light back towards an observer. To test the biological significance of these optical effects, we next conducted careful behavioural studies with flower naïve, free-flying bumblebees. To enable this research, we used casts of key petal surfaces and additionally constructed artificial stimuli.

If stimulus intensity was important, we would expect that bumblebees would spontaneously prefer to choose smoother surfaces, whilst if maintaining pigment-based colour signal integrity i.e. the constancy of colour irrespective of viewing angle (represented by spectral purity and/or colour contrast) was preferred by naïve bumblebees we would expect more visitations to conical or rough surfaces. If bee choices were random this would fit a null hypothesis position that petal cell shape does not serve a visual signalling role for bee pollinators. In multidirectional lighting conditions as might represent diffuse cloudy foraging conditions there was a significant spontaneous preference for bees landing on stimuli with conical or rough surfaces of vertically presented artificial flowers, showing that signal integrity is the explanation in these conditions that best explains the reason why flowering plants have conical cells.

In spotlight conditions that simulated direct sunlight there was no significant preference when bees travelled towards stimuli and the primary illumination source was behind the travel path of the bee; however, when bees had to travel in a direction towards the illumination source, we observed there was again a significant spontaneous preference for landing on stimuli with conical or rough surfaces. This shows that signal integrity promoted by conical cells is the primary reason flower petals frequently have conical shaped cells. It has been well established that flower colour pigments represent an efficient way for plants to colour flowers to best promote visits from important pollinators (van der Kooi et al. 2019), and maintaining the signal integrity of this signalling system appears to be of high value in how flowers evolve surface structures (Rhode et al. 2013). It would be valuable to test whether pollinators avoid approaching glossy flowers against the direction of incident sunlight in order to avoid uncertainty about the perceived flower colours.

\section{ACKNOWLEDGEMENTS}

We wish to thank Steffen Köhler for help with scanning electron microscopy and Waldemar Seidel for the precision mechanic workshop service. We thank Jair Garcia and Mani Shrestha for discussions. AGD acknowledges the Australian Research Council's Discovery Projects DP130100015 and DP160100161.

\section{APPENDICES}

Additional supporting information may be found in the online version of this article:

Appendix 1. Fig. S1: Artificial flowers

Appendix 2. Fig. S2: Positional preferences

Appendix 3. Fig. S3: 1st, 2nd 3rd, and 4th choices of bumblebee workers

Appendix 4. Fig. S4: Spectral reflectance of petals 
Appendix 5. Table S1: Percentage of white pixels in digital photos

Appendix 6. Table S2: Comparison between summarised responses of bumblebees and first responses of individual bumblebees

\section{REFERENCES}

Alcorn K, Whitney H, Glover B (2012) Flower movement increases pollinator preference for flowers with better grip. Funct Ecol 26: 941-947

Baumann K, Perez-Rodriguez M, Bradley D, Venail J, Bailey P, Jin H, Koes R, Roberts K, Martin C (2007) Control of cell and petal morphogenesis by R2R3 MYB transcription factors. Development 134:1691-1701

Blut C, Wilbrandt J, Fels D, Girgel EI, Lunau K (2012) The 'sparkle' in fake eyes - the protective effect of mimic eyespots in Lepidoptera. Entomologia experimentalis et applicata 143: 231-244

Chadwick AC, Kentridge RW (2015) 2015 The perception of gloss: A review. Vision Res 109: 221-235

Chittka L (1992) The colour hexagon: a chromaticity diagram based on photoreceptor excitations as a generalized representation of colour opponency. J Comp Physiol A 170:533-543

Comba L, Corbet SA, Hunt H, Outram S, Parker JS, Glover BJ (2000) The role of genes influencing the corolla in pollination of Antirrhinum majus. Plant Cell Environ 23:639-647

Daumer K (1956) Reizmetrische Untersuchungen des Farbensehens der Bienen. Z vergl Physiol 38: 413-478

Dyer AG (2012) Psychophysics of honey bee color processing in complex environments. In: Galizia CG, Eisenhardt D, Giurfa M (eds) Honeybee Neurobiology and Behavior, pp 303-314

Dyer AG, Whitney HM, Arnold SEJ, Glover BJ, Chittka L (2007) Mutations perturbing petal cell shape and anthocyanin synthesis influence bumblebee perception of Antirrhinum majus flower colour. Arthropod Plant Interact 1:45-55

Dyer AG, Boyd-Gerny S, McLoughlin S, Rosa MG, Simonov V, Wong BB (2012) Parallel evolution of angiosperm colour signals: common evolutionary pressures linked to hymenopteran vision. Proceedings of the Royal Society B: Biological Sciences 279:36063615

Ellis AG, Johnson SD (2009) The evolution of floral variation without pollinator shifts in Gorteria diffusa (Asteraceae). Am J Bot 96:793-801

Erber J, Kierzek S, Sander E, Grandy K. (1998) Tactile learning in the honeybee. J Comp Physiol A 183: 737 744

Galsterer S, Musso M, Asenbaum A, Fürnkranz D (1999) Reflectance measurements of glossy petals of
Ranunculus lingua (Ranunculaceae) and of non-glossy petals of Heliopsis helianthoides (Asteraceae). Plant Biol 1: $670-678$

Garcia JE, Hung Y-S, Greentree AD, Rosa MG, Endler JA, Dyer AG. (2017) Improved color constancy in honey bees enabled by parallel visual projections from dorsal ocelli. Proc Nat Acad Sci 114: 7713-7718.

Garcia JE, Shrestha M, Howard SR, Petersen P, Dyer AG (2019) Signal or cue: the role of structural colors in flower pollination. Current Zoology 65: 467-481

Garcia JE, Shrestha M, Rozo LO, Dekiwadia C, Field MR, Ma JS, Tran N, Dyer AG, Fox K, Greentree AD (2020) Iridescence and hydrophobicity have no clear delineation that explains flower petal micro-surface. Scientific Reports 10: 10685

Gkikas D, Argiropoulos A, Rhizopoulou S (2015) Epidermal focusing of light and modelling of reflectance in floral-petals with conically shaped epidermal cells. Flora 212:38-45

Glover BJ, Martin C (1998) The role of petal cell shape and pigmentation in pollination success in Antirrhinum majus. Heredity 80:778-784

Glover BJ, Whitney HM (2010) Structural colour and iridescence in plants: the poorly studied relations of pigment colour. Ann Bot 105: 505-511Gorton HL, Vogelmann TC (1996) Effects of epidermal cell shape and pigmentation on optical properties of Antirrhinum petals at visible and ultraviolet wavelengths. Plant Physiol 112:879-888

Gumbert A (2000) Color choices by bumble bees (Bombus terrestris): innate preferences and generalization after learning. Behav Ecol Sociobiol 48: 36-43

Hurlbert A (2007) Colour constancy. Curr Biol 17:R906R907

Ison JL, Tuan ESL, Koski MH, Whalen JS, Galloway LF (2019) The role of pollinator preference in the maintenance of pollen colour variation. Ann Bot 123: 951-960

Johnson SD, Midgley JJ (1997) Fly pollination of Gorteria diffusa (Asteraceae), and a possible mimetic function for dark spots on the capitulum. Am J Bot 84:429-436

Kay QON, Daoud HS, Stirton CH (1981) Pigment distribution, light reflection and cell structure in petals. Bot J Linn Soc 83:57-84

Kay QON (1988) More than the eye can see: the unexpected complexity of petal structure. Plants Today 1:109-114

Kevan (1978) Floral coloration, its colorimetric analysis and significance in anthecology. In: Richards AJ (ed) The Pollination of Flowers by Insects. Linnean Society Symposium Series No. 6, pp. 51-78Kevan PG, Lane MA (1985) Flower petal micro-texture is a tactile cue for bees. Proc Natl Acad Sci USA 82: 4750-4752 
Kraaij M, van der Kooi CJ (2019) Surprising absence of association between flower surface micro-structure and pollination system. Plant Biol J. doi:10.1111/plb.13071

Kühn A (1927) Über den Farbensinn der Bienen. Z vergl Physiol 5: 762-800

Kugler H (1935) Blütenökologische Untersuchungen mit Hummeln VII. Die Anlockung von ,Neulingen' durch Blüten. Planta 23: 692-714

Land EH (1977) The retinex theory of color vision. Sci Am 237:108-128

Landy MS (2007) A gloss on surface properties. Nature 447: 158-159

Lunau K (1990) Colour saturation triggers innate reactions to flower signals: flower dummy experiments with bumblebees. J Comp Physiol A 166:827-834

Lunau K (2016) Flower colour: How bumblebees handle colours with perceptually changing hues. Curr Biol 26: R229-R246

Lunau K, Maier EJ (1995) Innate colour preferences of flower visitors. J Comp Physiol A 177:1-19

Lunau K, Ren Z-X, Fan X-Q, Trunschke J, Pyke GH, Wang H (2020) Nectar mimicry: a new phenomenon. Sci Rep 10: 7039.

Lunau K, Wacht S, Chittka L (1996) Colour choices of naive bumble bees and their implications for colour perception. J Comp Physiol A 178:477-489

Maxwell JC (1857) 1. Experiments on colour as perceived by the eye, with remarks on colour-blindness. P Roy Soc Edinb 3: 299-301Menzel R (1979) Spectral Sensitivity and Color Vision in Invertebrates. In: Autrum $\mathrm{H}$ et al. (eds) Comparative Physiology and Evolution of Vision in Invertebrates. Handbook of Sensory Physiology vol 7/6/6A. Springer, Berlin, Heidelberg

Motoyoshi I, Nishida S, Sharan L, Adelson EH (2007) Image statistics and the perception of surface qualities. Nature 447: 206-209

Moyroud E, Glover BJ (2016) The physics of pollinator attraction. New Phytol 216:350-354. https://doi.org/10.1111/nph.14312

Moyroud E, Wenzel T, Middleton R, Rudall PJ, Banks H, Reed A, Mellers G, Killoran P, Westwood MM, Steiner U, Vignolini S, Glover BJ (2017) Disorder in convergent floral nanostructures enhances signalling to bees. Nature 550:469-474. doi: 10.1038/nature24285

Muth F, Papaj DR, Leonard AS (2015) Colour learning when foraging for nectar and pollen: bees learn two colours at once. Biol Lett: 1120150628Papiorek S, Rohde K, Lunau K (2013) Bees' subtle colour preferences: how bees respond to small changes in pigment concentration. Naturwissenschaften 100:633-643
Papiorek S, Junker RR, Lunau K (2014) Gloss, colour and grip: Multifunctional epidermal cell shapes in bee- and bird-pollinated flowers. PLoS ONE 9(11):e112013

Peitsch D, Fietz A, Hertel H, de Souza J, Ventura DF, Menzel R (1992) The spectral input systems of hymenopteran insects and their receptor-based colour vision. J Comp Physiol A 170:23-40

Reverté S, Retana J, Gómez JM, Bosch J (2016) Pollinators show flower colour preferences but flowers with similar colours do not attract similar pollinators. Annals of Botany 118: 249-257

Shrestha M, Dyer AG, Boyd-Gerny S, Wong BBM, Burd M (2013) Shades of red: bird-pollinated flowers target the specific colour discrimination abilities of avian vision. New Phytol 198:301-310

Shrestha M, Lunau K, Dorin A, Schulze B, Bischoff M, Burd M, Dyer A (2016) A world without the birds and the bees: flowers of Macquarie Island. Plant Biology 18:842-850

Shrestha M, Burd M, Garcia JE, Dorin A, Dyer AG (2019) Colour evolution within orchids depends on whether the pollinator is a bee or a fly. Plant Biol J 21: 745-752

Smithson A, McNair MR (1996) Frequency-dependent selection by pollinators: mechanisms and consequences with regard to behaviour of bumblebees Bombus terrestris (L.) (Hymenoptera: Apidae). J Evol Biol 9: 571-588Skorupski P, Chittka L (2011) Is colour cognitive? Opt Laser Technol 43:251-260

Spaethe J, Tautz J, Chittka L (2001) Visual constraints in foraging bumblebees: Flower size and color affect search time and flight behavior. Proc Natl Acad Sci USA 98:3898-3903.

Sprengel CK (1793) Das entdeckte Geheimnis der Natur im Bau und in der Befruchtung der Blumen. Vieweg, Berlin - Reprint 1972, Cramer, Lehre.

Stavenga DG, van der Kooi CJ (2016) Coloration of the Chilean Bellflower, Nolana paradoxa, interpreted with a scattering and absorbing layer stack model. Planta 243:171-181

Van der Kooi CJ, Wilts BD, Leertouwer HL, Staal M, Elzenga JTM, Stavenga DG (2014) Iridescent flowers? Contribution of surface structures to optical signalling. New Phytol 203:667-673

Van der Kooi CJ, Elzenga JT, Staal M, Stavenga DG (2016) How to colour a flower: on the optical principles of flower coloration. Proc R Soc B 283:20160429. doi: 10.1098/rspb.2016.0429

Van der Kooi CJ, Elzenga JT, Dijksterhuis J, Stavenga DG (2017) Functional optics of glossy buttercup flowers. Journal of the Royal Society Interface 14 (127)

van der Kooi CJ, Dyer AG, Kevan PG, Lunau K (2019) Functional significance of the optical properties of flowers for visual signalling. Annals of Botany 123: 263-276 
Vignolini S, Davey MP, Bateman RM, Rudall PJ, Moyroud E, Tratt J, Malmgren S, Steiner U, Glover BJ (2012) The mirror crack'd: both pigment and structure contribute to the glossy blue appearance of the mirror orchid, Ophrys speculum. New Phytol 196: 1038-1047

Vignolini S, Moyroud E, Hingant T, Banks H, Rudall PJ, Steiner U, Glover B J (2015) The flower of Hibiscus trionum is both visibly and measurably iridescent. New Phytol 205:97-101

von Frisch K (1915) Der Farbensinn und Formensinn der Biene. Zool Jb Physiol 35: 1-182

Wester P, Lunau K (2017) Plant-pollinator communication. In: Becard G (ed) Advances in Botanical Research, Vol. 82, How Plants Communicate with their Biotic Environment; pp. 225-257; Academic Press, Amsterdam

Whitney HM, Chittka L, Bruce TJ, Glover BJ (2009a) Conical epidermal cells allow bees to grip flowers and increase foraging efficiency. Curr Biol 19:948-953

Whitney HM, Federle W, Glover BJ (2009b) Grip and slip. Commun Integr Biol 2: 505-508

Whitney HM, Kolle M, Andrew P, Chittka L, Steiner U, Glover BJ (2009c) Floral iridescence, produced by diffractive optics, acts as a cue for Aanimal pollinators. Science 323:130-133

Whitney HM, Rands SA, Elton NJ, Ellis AG (2012) A technique for measuring petal gloss, with examples from the Namaqualand flora. PLoS One 7: e29476

Whitney HM, Bennett KV, Dorling M, Sandbach L, Prince D, Chittka L, Glover BJ (2011a) Why do so many petals have conical epidermal cells? Ann Bot 108:609616

Whitney HM, Glover BJ, Walker R, Ellis AG (2011b) The contribution of epidermal structure to flower colour in the South African flora. Curtis's Bot Mag 28:349-371

Whitney HM, Poetes R, Steiner U, Chittka L, Glover BJ (2011c) Determining the contribution of epidermal cell shape to petal wettability using isogenic Antirrhinum lines. PLoS ONE 6:e17576

Whitney HM, Reed A, Rands SA, Chittka L, Glover BJ (2016) Flower iridescence increases object detection in the insect visual system without compromising object identity. Curr Biol 26:802-808. doi 10.1016/j.cub.2016.01.026

Wyszecki G, Stiles WS (1982) Color Science: concepts and methods, quantitative data and formulae. Wiley, New York 